\title{
Effects of perch availability on performance, carcass characteristics, and footpad lesions in broilers
}

\author{
Z. Kiyma, K. Küçükyılmaz, and A. Orojpour \\ Department of Animal Science, Eskisehir Osmangazi University, Eskişehir, Turkey \\ Correspondence to: Z. Kiyma (zkiyma@gmail.com)
}

Received: 19 August 2015 - Revised: 10 December 2015 - Accepted: 12 January 2016 - Published: 19 January 2016

\begin{abstract}
In the modern broiler industry, solutions are still being sought to improve conditions or eliminate problems related to issues such as animal welfare, health, and meat quality brought by intensive production systems. Therefore, this experiment was conducted to study effects of perching on growth performance, carcass characteristics, and footpad lesions (FPLs) in broiler chickens. A total of 300 broiler chicks (Ross 308) were distributed into control and perch groups with three replicates including equal numbers of males and females. The perch group contained two single perches in each pen.

Analysis of camera records revealed that on average $7.36 \%$ of the birds using perches. Perch use did not have any effect on growth performance $(P>0.05)$, but had a positive effect on FPLs $(P<0.001)$. Carcass yield and proportions of carcass parts were not affected by perch availability $(P>0.05)$. Thigh and breast meat color was less yellow $(P<0.005)$ in the perch group compared to the control group, where breast meat color was more red $(P<0.01)$. Birds in the perch group had brighter breast meat $(P<0.001)$. The weight of livers in the perch group was lower than in the control group $(P<0.01)$.

These findings suggest that perch use has positive effect on FPLs. The reduction of redness in the breast could indicate that perch use may have a positive effect on breast inflammation. The potential positive effects of adapting perch use to intensive conditions should be further investigated.
\end{abstract}

\section{Introduction}

Poultry products, mainly from broilers, have come into prominence in human nutrition as valuable and economical food. It is obvious that broilers with the best feed conversion ratio of domesticated land-based animals will retain their importance in the future as long as the human population continues to increase. Broiler production has increased incrementally and become one of the most intensive animal production systems. High stocking density together with genetic selection for higher feed conversion efficiency and growth rate has caused behavioral restriction and uneven use of space. Therefore, broilers reared using standard commercial practice suffer from many welfare problems (SCAHAW, 2000).

Animal welfare and health, meat quality, production intensity, performance, and housing conditions such as air and litter quality have always been current issues in intensive broiler production systems. Lack of exercise and/or sitting on low-quality litter for extended periods of time have been reported to be the main causes of leg weakness and skin lesions (Bessei, 2006). In order to improve some of these conditions, perch use has been tested by several studies. Perching is an instinctive behavior in domesticated birds (Blokhuis, 1984). However, there are some problems with perch use in broilers. Broilers' perching behavior is not as common as in laying hens (Faure and Jones, 1982), probably due to their fast growth rate and therefore heavy body weight in early ages, and they tend to exercise less with advancing age (LeVan et al., 2000). Broilers' short life also may contribute to low perch use. Several studies show that broiler chicks spend little time on perches in early weeks; therefore, they would have a few weeks to use perches before they get too heavy. On the other hand, if broilers do not use perches, already restricted space could be more restrained by placing perches in the housing. The short production cycle may also be a problem for setting up and removing perches in broiler housing. 
Despite all these adverse factors, various beneficial effects of perching have been reported in broiler production. Theoretically, perches have the potential to reduce stocking density at floor level (Hughes and Elson, 1977), decrease health problems related with stocking density, such as reduced leg problems through exercise (Haye and Simons, 1978); improve heat stress conditions by allowing air flow beneath the perches to help thermoregulation of birds (LeVan et al., 2000); decrease aggression; and promote more even distribution of birds within the pen space (Ventura et al., 2012).

Spatial confinement causes behavioral restrictions in broilers, which tend to move less at higher animal densities (Newberry and Hall, 1990). While lack of exercise was reported to increase the incidence of leg abnormalities, beneficial effects of perching diminished leg problems by increasing animal mobility in broilers (Haye and Simons, 1978). In broiler production, FPLs have become a serious welfare and economical issue. FPLs may have a direct economic impact through reducing the quality of chicken feet, which are highly demanded in the export market (Shepherd and Fairchild, 2010). Severe FPLs are considered to be painful for the birds (Michel et al., 2012), may cause a deteriorated state of animal's health, and can even be a gateway for pathogens (Ekstrand et al., 1997). In the recent years, there has been a marked increase in the frequency of FPLs in the world. Prevalence of severe FPLs has been reported to the levels of 38-70\% in regular, modern fast-growing broilers (Allain et al., 2009; Gouveia et al., 2009). Hashimoto et al. (2011) reported the incidence of FPLs as 13.1, 33.3, 33.4, and $20.2 \%$ for the scores of $0,1,2$, and 3 , respectively. In that study, the incidence of FPLs in 42 flocks ranged from 31.9 to $99.5 \%$. FPLs can be caused by several risk factors, such as litter moisture and type, diet composition, bird weight, and sex; all of these factors may interact with each other and make it difficult to understand the etiology of FPLs (Mayne, 2005). In the literature, litter quality (litter type, moisture, ammonia content) is at the beginning of the list of factors that can cause FPLs (Martland, 1985; Mayne, 2005). A limited improvement of footpad health by use of simple barrier perches has been reported (Ventura et al., 2010). Ventura et al. (2012) reported that simple barrier perches could be a cheap and simple strategy to improve broiler health and welfare by creating a more complex environment to increase activity level and providing more space for resting, as well as decreasing aggression. Use of perches has been reported among environmental improvements that have been shown to increase activity and welfare of broilers in sheds (SCAHAW, 2000).

The present study was conducted to evaluate the perch use ratio of broilers and the effects of perch availability on performance, carcass and certain meat quality characteristics, and FPLs in broilers.

\section{Materials and methods}

The following procedures related to animal handling and sample collections were approved by the Eskisehir Osmangazi University Local Ethics Committee of Animal Experiments (HAYDEK-421-2014). The study was conducted at the Poultry Research Unit of Animal Science Department, Faculty of Agriculture, Eskisehir Osmangazi University, Eskişehir, Turkey.

\subsection{Animals and diets}

A total of three hundred 1-day-old mixed-sex broiler chicks (Ross 308) with an average initial body weight of $49.1 \pm 1.07 \mathrm{~g}$ were obtained from a commercial hatchery. The chicks were randomly assigned to control and perch groups, which each contained 150 birds. The experiment was arranged as a completely randomized design with two treatments that were further subdivided into three replicates, each containing 50 birds ( 25 males and 25 females). Each replicate was assigned to a clean floor pen $(2.5 \times 1.5 \mathrm{~m})$ covered with $5-6 \mathrm{~cm}$ of pine wood shavings and equipped with one hanging bell drinker, two tube-type feeders, and electrical heaters. Pens in the perch group additionally included perches as described below. The stocking density was 13 birds per square meter of floor space. The room temperature was gradually decreased from $33^{\circ} \mathrm{C}$ at chick arrival to $23^{\circ} \mathrm{C}$ on day 22 and thereafter kept constant until trial termination on day 39 . Chicks received $23 \mathrm{~h}$ of light per day during the experiment. The house was ventilated with adjustable windows. Birds were vaccinated against the infectious bursal disease and Newcastle disease viruses via drinking water at 10 and 14 days of age, respectively.

Ingredients and nutritional composition of the starter and grower diets are presented in Table 1 . The diet was a typical corn-wheat-soybean diet that was formulated to meet or exceed all nutrient recommendations published in the Ross rearing guidelines (Aviagen, 2007) and did not contain antibiotic growth promoters, coccidiostats, or any other performance enhancer. The diet in mash form and water were provided ad libitum. Chemical compositions of diets were determined according to the methods described in AOAC (1990) and the metabolic energy was calculated as described in TSE (1991).

The birds were weighed on a pen basis on days 1,21 , and 39 to determine body weight through relevant experimental periods. Feed intake within each subgroup was calculated for the first 3-week period (days 1-21) and for the complete growth period (days 1-39) by subtracting residual feed from the offered feed. The feed conversion ratio was calculated as the ratio of feed intake to body weight gain ( $\mathrm{g}$ feed/g gain). The ratio was adjusted for weight of chicks at day 1 and weight of dead birds for each pen. Mortality was recorded daily and expressed as a percentage of the initial number of chicks. 
Table 1. Ingredient and chemical composition of starter and grower diets.

\begin{tabular}{lrrlrr}
\hline $\begin{array}{l}\text { Ingredients } \\
\left(\mathrm{g} \mathrm{kg}^{-1}\right)\end{array}$ & $\begin{array}{r}\text { Starter } \\
\text { diet }\end{array}$ & $\begin{array}{r}\text { Grower } \\
\text { diet }\end{array}$ & $\begin{array}{l}\text { Analyzed and } \\
\text { calculated nutrient }\end{array}$ & $\begin{array}{r}\text { Starter } \\
\text { diet }\end{array}$ & $\begin{array}{r}\text { Grower } \\
\text { diet }\end{array}$ \\
\hline Corn & 368.00 & 420.00 & Dry matter $(\%)$ & 88.22 & 88.11 \\
Wheat & 200.00 & 200.00 & Crude protein $(\%)$ & 22.00 & 20.74 \\
Soybean meal $(48 \%)$ & 355.00 & 300.00 & ME (kcal kg-1) & 3050 & 3200 \\
Soybean oil & 35.00 & 45.00 & Crude Fat $(\%)$ & 4.77 & 5.90 \\
Calcium carbonate & 16.00 & 10.00 & Crude cellulose (\%) & 2.58 & 2.44 \\
Dicalcium phosphate & 18.00 & 16.50 & Crude ash $(\%)$ & 6.64 & 5.88 \\
Sodium chloride & 2.50 & 3.50 & Calcium $(\%)$ & 1.30 & 1.19 \\
Vit.-min. premix & 2.50 & 2.50 & Available $P(\%)$ & 0.46 & 0.40 \\
Methionine & 2.00 & 2.50 & Lysine $(\%)$ & 1.18 & 1.00 \\
& & & Methionine $(\%)$ & 0.54 & 0.50 \\
\hline
\end{tabular}

* Provides the following per kilogram of diet: $12000 \mathrm{IU}$ trans-retinol; $1500 \mathrm{IU}$ cholecalciferol; $75 \mathrm{mg} \alpha$-tocopherol acetate; $5 \mathrm{mg}$ vitamin $\mathrm{K}_{3} ; 3 \mathrm{mg}$ vitamin $\mathrm{B}_{1} ; 6 \mathrm{mg}$ vitamin $\mathrm{B}_{2} ; 5 \mathrm{mg}$ vitamin $\mathrm{B}_{6} ; 0.03 \mathrm{mg}$ vitamin $\mathrm{B}_{12} ; 40 \mathrm{mg}$ nicotinamide; $10 \mathrm{mg}$ pantothenic acid; $0.75 \mathrm{mg}$ folic acid; $0.075 \mathrm{mg}$ D-biotin; $375 \mathrm{mg}$ choline, $80 \mathrm{mg} \mathrm{Mn} ; 40 \mathrm{mg} \mathrm{Fe}$; $60 \mathrm{mg} \mathrm{Zn;} 5 \mathrm{mg} \mathrm{Cu} ; 0.5 \mathrm{mg} \mathrm{I} ; 0.2 \mathrm{mg} \mathrm{Co} ; 0.15 \mathrm{mg} \mathrm{Se}$.

While determining the final body weight at day 39, FPL scores of all birds were concurrently evaluated. For the scoring, FPLs were assigned to one of the following four classes: 0 - no lesions, discoloration, or scars; 1 - mild lesions, parts of footpad discolored to light brown; 2 - large or multiple tumors, discoloration of footpad to dark brown; 3 - severe deep lesions, ulcers, and scabs (Van der Aa, 2008).

\subsection{Pen design and perching observation}

Two wooden perches at a height of $12 \mathrm{~cm}$ and measuring $3 \times 5 \times 100 \mathrm{~cm}$ (thickness $\times$ width $\times$ length) were placed horizontally between feeders and the drinker in each pen of the perch group as shown in Fig. 1. Each perch had a $25 \mathrm{~cm}$ wooden mount at each end forming an "I" shape and providing a total of $150 \mathrm{~cm}$ of linear perching space. A total length of $300 \mathrm{~cm}$ provided $6 \mathrm{~cm}$ of perching space per bird in the perch group. Camcorders were positioned over each pen of only the perch group and light colored wooden perches were painted in black in order to easily observe the number of broilers perching. Perches were placed in pens within the first week and pens were recorded $24 \mathrm{~h}$ a day starting from the second week until end of the experiment. Then the records were viewed for $15 \mathrm{~min}$ of every consecutive hour of consecutive days (i.e. 00:00-00:15, 02:00-02:15 LT, and so on) and number of birds displaying a full perching behavior, sitting at least $5 \mathrm{~s}$, were counted. Crossing over the perch or walking on the perch for a short time was not counted as perching. The data were analyzed for average perching throughout the study, perching by age (second through fifth week), and daytime (08:00 to 18:15 LT) versus nighttime (20:00-06:15 LT).

\subsection{Sample collection and analysis}

Broilers were all slaughtered at 39 days of age. To determine the carcass yield, relative weight of the carcass cuts, inter-

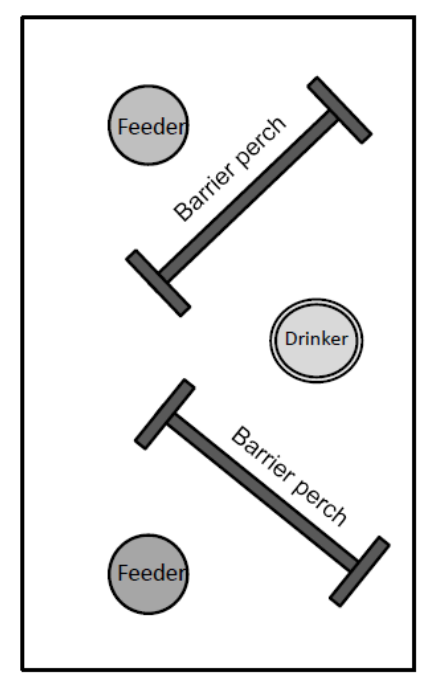

(a)

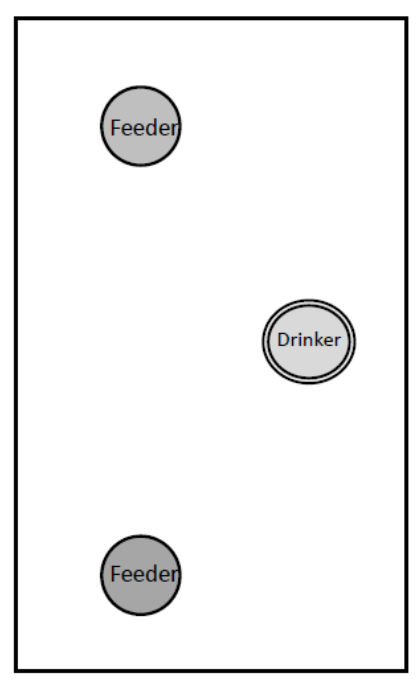

(b)
Figure 1. Design of the perch and layout of the experimental pens (a) with barrier perches (perch group) and (b) without barrier perch (control group).

nal organ weight, and meat quality characteristics, 16 birds ( 8 male, 8 female) representing the average weight of the group ( $\pm 5 \%)$ were selected from each group. Then, 32 sampled birds were slaughtered by severing the jugular vein in the experimental processing unit $8 \mathrm{~h}$ after feed withdrawal. The carcasses were immersed in hot water $\left(60^{\circ} \mathrm{C}\right.$ for $\left.62 \mathrm{~s}\right)$, plucked, and manually eviscerated. Then, the whole carcass was immediately weighed, and hot carcass yield was determined as a percentage of pre-slaughter live body weight. The carcass was cut into parts, and breast (including thigh and drumstick), wings, and back were weighed. The percentage weight of the eviscerated carcasses was calculated as the ratio between the eviscerated carcass and live body weight. The 
Table 2. Effects of perch availability on the performance indices and footpad lesion score of broiler chickens.

\begin{tabular}{|c|c|c|c|c|c|c|c|c|c|}
\hline & \multicolumn{4}{|c|}{1 to 21 days } & \multicolumn{4}{|c|}{1 to 39 days } & \multirow[b]{2}{*}{$\begin{array}{l}\text { Foot pad } \\
\text { lesion } \\
\text { score }\end{array}$} \\
\hline & $\begin{array}{l}\text { Body } \\
\text { weight } \\
\text { (g) }\end{array}$ & $\begin{array}{l}\text { Feed } \\
\text { intake } \\
(\mathrm{g})\end{array}$ & $\begin{array}{l}\text { Feed } \\
\text { conversion } \\
\text { ratio }\end{array}$ & $\begin{array}{l}\text { Mortality } \\
(\%)\end{array}$ & $\begin{array}{l}\text { Body } \\
\text { weight } \\
\text { (g) }\end{array}$ & $\begin{array}{l}\text { Feed } \\
\text { intake } \\
(\mathrm{g})\end{array}$ & $\begin{array}{l}\text { Feed } \\
\text { conversion } \\
\text { ratio }\end{array}$ & $\begin{array}{l}\text { Mortality } \\
(\%)\end{array}$ & \\
\hline Control & 994 & 1412 & 1.494 & 1.33 & 2608 & 4672 & 1.826 & 1.33 & $2.02^{\mathrm{b}}$ \\
\hline Perch & 994 & 1406 & 1.487 & 1.38 & 2610 & 4648 & 1.814 & 2.00 & $1.32^{\mathrm{a}}$ \\
\hline SEM & 851 & 13.54 & 0.012 & 1.36 & 248 & 55.6 & 0.009 & 1.24 & 0.10 \\
\hline$P$ value & 0.9643 & 0.7697 & 0.6775 & 0.9784 & 0.9347 & 0.7752 & 0.4190 & 0.7247 & 0.0001 \\
\hline
\end{tabular}

$a, b$ Values with the different superscript in the same column are different $(P<0.05)$.

percentages of the breast, leg, wing, and back were calculated in relation to the eviscerated carcass weight. The weights of selected internal organs (gizzard, liver, spleen, and pancreas) and abdominal fat were weighed and expressed as a percentage of live body weight.

The breast and thighs were separated with their skin on and the color values of these samples were determined according to the CIELAB method using a Minolta CR-300 (USA) colorimeter apparatus. Lightness, redness, and yellowness values, $L^{*}, a^{*}$, and $b^{*}$, respectively, were represented according to this method. Water-holding capacity (WHC) was measured by means of the centrifuging method (Castellini et al., 2002). Drip loss percentage was determined as described by Fanatico et al. (2005).

\subsection{Statistical analysis}

The experiment was carried as a completely randomized design with two treatments. Data were analyzed by ANOVA using the GLM procedure of SAS Institute (2001). An arcsin transformation was applied to the percentage values (i.e. mortality and number of broilers on perch) before testing for differences. Additionally, a two-way ANOVA test using the REPEATED statement in GLM procedure of the SAS Institute (2001) with repeated measurements on both factor levels was performed with age and time of day as factors that have the potential to affect the number of perched birds. The significant differences among means of the treatments were determined by using Duncan's multiple range test with $5 \%$ probability.

\section{Results}

Perching behavior or number of birds using a perch was affected by age $(P<0.05)$ but not by the time of day (daytime: from 08:00 to 18:15 LT; nighttime: 20:00-06:15 LT, data not shown). Interaction between age and time of day with respect to perching was not important $(P>0.05)$. Numbers of birds used perches from the second week until the end of the fifth week were shown as a percentage of total birds in Fig. 2. Average perch use was $7.36 \%$ over the course of the

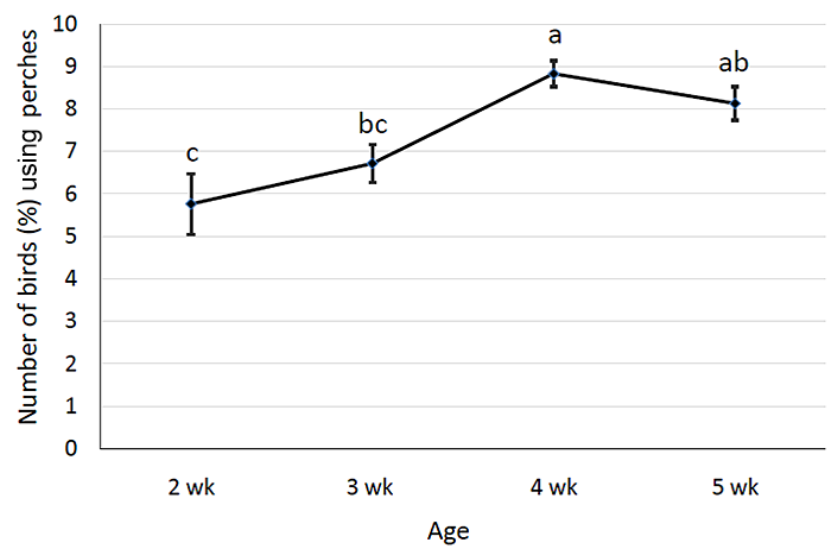

Figure 2. Perching ratio of broilers chickens throughout advancing age. Data are means of three replicates that each contained 50 birds per pen. Means having different letter differ $(P<0.05)$.

study. Overall perching behavior increased by age starting from the second through fourth week $(5.76,6.72,8.83$, and $8.13 \%$ for the second, third, fourth, and fifth week, respectively). Highest perch use was attained at the fourth week and at this age perching ratio was higher $(P<0.05)$ than the second and third week but similar with that of the fifth week $(P>0.05)$.

Performance traits of broilers, including body weight, feed intake, feed conversion ratio, mortality, and FPL score are shown in Table 2. Availability of perches had no effect on body weight, feed intake, and feed conversion ratio of broiler chickens fed for 39 days (i.e. intervals of 1 to 21,21 to 39 , and 1 to 39 days; $P>0.05$ ). However, it had a beneficial effect on FPL score, which decreased by approximately $34 \%$ $(P<0.0001)$.

The broiler chicken carcass characteristics are presented in Table 3. The meat cut carcass yield and proportional weights of carcass parts (i.e. breast, thigh, wing, and back) were not affected by perch availability $(P>0.05$; Table 3$)$.

The effects of perch availability on $L^{*}, a^{*}, b^{*}$ color values, drip loss, and WHC of breast and thigh meat of broilers are presented in Table 4. Color $a^{*}$ and $b^{*}$ values in thigh and 
Table 3. Effects of perch availability on carcass characteristics of broilers.

\begin{tabular}{llllll}
\hline & $\begin{array}{l}\text { Carcass } \\
\text { yield } \\
(\%)\end{array}$ & $\begin{array}{l}\text { Thigh } \\
\text { yield } \\
(\%)\end{array}$ & $\begin{array}{l}\text { Breast } \\
\text { yield } \\
(\%)\end{array}$ & $\begin{array}{l}\text { Wing } \\
\text { yield } \\
(\%)\end{array}$ & $\begin{array}{l}\text { Back } \\
\text { yield } \\
(\%)\end{array}$ \\
\hline Control & 75.95 & 27.70 & 38.8 & 9.49 & 23.96 \\
Perch & 75.70 & 28.08 & 38.8 & 9.63 & 23.40 \\
SEM & 0.29 & 1.58 & 0.52 & 0.20 & 0.32 \\
$P$ value & 0.5638 & 0.5268 & 0.9554 & 0.6398 & 0.2321 \\
\hline
\end{tabular}

breast meat of the birds in the control group was higher than that of the perch group, while the opposite was observed in $L^{*}$ values of breast meat. Breast meat $L^{*}$ values in the perch group were higher $(P<0.01)$ than the values in the control group. The drip loss was not affected by perch availability $(P>0.05)$. There was no difference in WHCs of breast meat; however, birds in the perch group had a lower WHC of thigh meat than control birds $(P<0.01)$.

Measurements of some internal organs and abdominal fat weight as percentage of body weight are given in Table 5 . Proportional weights of the gizzard, spleen, and pancreas were not affected by perch availability $(P>0.05)$, whereas the weight of the livers was altered $(P<0.01)$. Compared to the control group, perch availability significantly reduced the proportional weight of liver. Weight of the abdominal fat was not affected by perch availability $(P>0.05)$.

\section{Discussion}

Use of perches has been suggested as a potential addition to improve the welfare and health status of the broilers (SCAHAW, 2000). However, broilers' perching behavior is not as common as in laying hens, as reported in several studies. In this study, $6 \mathrm{~cm}$ of linear perching space would allow $40 \%$ of the birds to perch simultaneously. However, on average $7.36 \%$ of broiler chickens used perches at the same time throughout the study, and the highest perching ratio was $8.83 \%$ at the fourth week. Therefore, it is important to make the right decision on the total length of the perch for efficient use of the restricted space available, something that is critical and always one of the main issues in broiler production. The perching ratio increased up to the fourth week, and then the increase ceased at the fifth week. A similar pattern for perching behavior has been reported in other studies (Pettit-Riley and Estevez, 2001; LeVan et al., 2000). Ventura et al. (2012) also reported a general trend for different density treatments $\left(8,13\right.$, and 18 birds $\left.\mathrm{m}^{-2}\right)$ that perching increased up to the fourth week and then declined. Hongchao et al. (2013) reported an average of $7.4 \%$ perching, with the maximum perching ratio occurring at the fifth week comparable to the current study. Although perching behavior data from this study are consistent with the recent literature, re- sults of older studies may show differences from recent studies, including this study. Hughes and Elson (1977) reported a much higher perching ratio $(27 \%)$ at 8 weeks of age. In that study, the birds had lower growth rates $(1861 \mathrm{~g}$ at the 56th day). Comparison of these older data with current data suggests that broilers' mobility is reduced along with advancing age due to fast body mass increase, as reported by Newberry and Hall (1990). Results of Nielsen's (2004) study, in which slow-growing broiler strains showed a higher perching ratio, also points out that perching behavior is affected adversely by fast body mass increase. On the other hand, some modifications in perches may enhance broiler's perching rate in certain circumstances, such as in high ambient temperatures or under heat stress conditions. For example, watercooled perches were favored by broilers under heat stress conditions and the perching rate peaked at $16.6 \%$ (Zhao et al., 2013), which is much higher than the rate in current study $(8.13 \%)$, at the fifth week of age.

In this study, availability of perches had no affect on growth performance of broilers. Similar results were reported by Pettit-Riley and Estevez (2001), Estevez et al. (2002), and Ventura et al. (2012). Although Zhao et al. (2013) reported beneficial effects of cooled perching on feed conversion ratio and body weight gain, these effects were related to a thermoregulatory advantage of the cooled perches. Availability of perching might not affect these criteria, probably due to relatively low use of the perches by fast-growing broilers.

Perch availability had a beneficial effect on FPL score that was $34 \%$ lower in the perch group (1.32) than the control group (2.02). Furthermore, individual birds that were severely affected were observed to have reduced feed intake in the current study. Supporting the current results, perch availability tended to prevent FPLs in other studies (Ventura et al., 2010, 2012; Hongchao et al., 2013). Although litter quality was not examined, a potential cause of a lower FPL score seems to be a better litter quality that can be related to the perch availability. It seems that use of perches might have provided a dryer and cleaner surface for birds to stand on or lie down on. Also, perch availability might help to improve litter quality by decreasing bird density at floor level by clearing off some of the birds from the ground and allowing the surface to dry faster. A higher incidence of contact dermatitis has been related to increased level of ammonia in combination with higher ambient temperature, moisture content of litter, and accelerated microbial activity in broiler houses (Bessei, 2006).

Carcass yield and proportional weights of carcass parts (i.e. breast, thigh, wing, and back) were not affected by perch availability in this study. Zhao et al. (2013) reported similar results with regard to carcass yield and proportions of carcass parts. Low perch use in the perch group, along with similar growth performance, may explain similar proportion of carcass parts in both groups in the current study.

In this study, perch availability decreased color $a^{*}$ values of thigh and breast meat. Currently, there are limited data on 
Table 4. Effects of perch availability on the $L^{*}, a^{*}$ and $b^{*}$ color values, drip loss, and water-holding capacity (WHC) of thigh and breast meat.

\begin{tabular}{|c|c|c|c|c|c|c|c|c|c|c|}
\hline & \multicolumn{5}{|c|}{ Thigh meat } & \multicolumn{5}{|c|}{ Breast meat } \\
\hline & $L^{*}$ & $a^{*}$ & $b^{*}$ & WHC & $\begin{array}{l}\text { Drip } \\
\text { loss }\end{array}$ & $L^{*}$ & $a^{*}$ & $b^{*}$ & WHC & $\begin{array}{l}\text { Drip } \\
\text { loss }\end{array}$ \\
\hline Control & 59.9 & 8.05 & $8.20^{\mathrm{a}}$ & $65.6^{\mathrm{a}}$ & 0.667 & $56.29^{\mathrm{b}}$ & $8.57^{\mathrm{a}}$ & $8.36^{\mathrm{a}}$ & 58.4 & 1.75 \\
\hline Perch & 60.26 & 6.61 & $7.01^{b}$ & $63.4^{\mathrm{b}}$ & 0.555 & $59.73^{\mathrm{a}}$ & $6.63^{b}$ & $6.80^{\mathrm{b}}$ & 59.5 & 1.66 \\
\hline SEM & 0.63 & 0.53 & 0.28 & 0.59 & 0.05 & 0.56 & 0.49 & 0.26 & 0.66 & 0.16 \\
\hline$P$ value & 0.7534 & 0.0678 & 0.0066 & 0.0068 & 0.1182 & 0.0002 & 0.0095 & 0.0002 & 0.1297 & 0.7134 \\
\hline
\end{tabular}

a, b Values with the different superscript in the same column are different $(P<0.05)$.

Table 5. Effects of perch availability on weight (percent of live body weight) of some internal organs and abdominal fat of broiler.

\begin{tabular}{llllll}
\hline & $\begin{array}{l}\text { Gizzard } \\
(\%)\end{array}$ & $\begin{array}{l}\text { Liver } \\
(\%)\end{array}$ & $\begin{array}{l}\text { Spleen } \\
(\%)\end{array}$ & $\begin{array}{l}\text { Pancreas } \\
(\%)\end{array}$ & $\begin{array}{l}\text { Abd. fat } \\
(\%)\end{array}$ \\
\hline Control & 1.33 & $1.94^{\mathrm{a}}$ & 0.096 & 0.185 & 1.01 \\
Perch & 1.36 & $1.73^{\mathrm{b}}$ & 0.083 & 0.181 & 1.21 \\
SEM & 0.05 & 0.05 & 0.2053 & 0.007 & 0.09 \\
$P$ value & 0.6590 & 0.0079 & 0.2053 & 0.7256 & 0.1167 \\
\hline
\end{tabular}

$a, b$ values with the different superscript in the same column are different $(P<0.05)$.

meat color in relation to perch availability in the literature. The reddened appearance of breast and thigh meat could be as a result of regular contact of the breast and thigh skin with litter, which usually has an increasing moisture level, particularly after the fifth week. Rapidly growing chickens spend more time (from $75 \%$ in the first week to $90 \%$ at 5 weeks of age) resting in a sitting or lying position as they grow (Bessei, 1992), and they place most of their body weight on the keel during resting. The birds must often stand on and lie down on their own waste and wet litter. Therefore, ammonia produced by the decomposing organic material may irritate the breast skin in particular. The redness of the breast was clearly associated with breast irritation that was scored as 0 for no irritation or redness of the breast, 1 for slight discoloration (redness) of the breast, and 2 for large discoloration (Jong et al., 2014). Contact dermatitis has been related to extremely long sitting and lying times and poor litter quality (Bessei, 2006). As observed in the current study, thinner feather coverage along with sitting on litter for a long time from the third week of age might also contribute to the reddened appearance of the meat. Therefore, perch availability might decrease contact of the breast with litter and consequently lead to reduced $a^{*}$ values of meat color.
Perch availability reduced WHC of the thigh in this study. Currently, there are a very limited number of studies examining meat quality in relation to perch availability. The current results are inconsistent with Zhao et al. (2013), who reported that decreased drip and cooking losses in broiler meat with cool perches indicated a beneficial influence on meat quality. However, in that study, a slight increase in drip loss was attributed to the detrimental effect of high stocking density, while decreases in drip and cooking losses were related to enhanced thermolysis from the use of cool perches. In the current study, reduced WHC of the thigh in the perch group could be related to perching being an exercise that has been reported to affect the rate of postmortem glycolysis, resulting in a lower WHC in red meat (Cheng and Sun, 2008).

According the EFSA (2015), liver weight could be a measure for physiological indicators of stress and welfare that could be linked to presence/absence of perches. Liver weights were lower in the perch group in this study. This result could be related to reduce stress resulting from the environmental addition of perches and increased activity (SCAHAW, 2000) as well as reduced pain (Michel et al., 2012) due to fewer FPLs.

These results suggest that perch availability has no effect on broiler performance. However, in spite of broilers' limited use of perches, perch availability may have a positive impact on FPLs, welfare, and meat quality, probably through increased exercise and utilization of vertical space and therefore reduced density accompanied with better litter quality. These impacts may be more pronounced in unfavorable conditions such as in poor bedding conditions. Overall, the body of literature on the use of perches in broilers is mostly limited to perch position and type. Potential beneficial effects of perch use with respect to animal welfare and meat quality performance should be further investigated.

Author contributions. Z. Kiyma and K. Küçükyılmaz designed and carried out the experiment and prepared the manuscript. A. Orojpour performed the statistical analysis.

Edited by: K. Wimmers

Reviewed by: two anonymous referees 


\section{References}

Allain, V., Mirabito, L., Arnould, C., Colas, M., Le Bouquin, S., Lupo, C., and Michel, V.: Skin lesions in broiler chickens measured at the slaughterhouse: relationships between lesions and between their prevalence and rearing factors, Brit. Poultry Sci., 50, 407-417, 2009.

AOAC: Official Methods of Analysis, 15th Edn., Association of official analytical chemists, Washington, D.C., 1990.

Aviagen: Broiler Nutrition Specifications, Aviagen Inc. Newbrigde, Scotland, UK, 2007.

Bessei, W.: The behaviour of broilers under intensive management conditions, Arch. Geflügelk., 56, 1-7, 1992.

Bessei, W.: Welfare of broilers: A review, Worlds Poultry Sci. J., 62, 455-466, 2006.

Birgül, Ö. B., Mutaf, S., and Alkan, S.: The Effects of Different Perch Systems on Morphological and Chemical Traits of Tibia and Femur Bones in Broilers, Kafkas Univ. Vet. Fak. Derg., 17, 773-779, 2011.

Blokhuis, H. J.: Rest in poultry, Appl. Anim. Behav. Sci., 12, 289 303, 1984

Castellini, C., Mugnai, C., and Dal Bosco, A.: Effect of organic production system on broiler carcass and meat quality, Meat Sci., 60, 219-225, 2002.

Cheng, Q. and Sun D. W.: Factors affecting the water holding capacity of red meat products: A review of recent research advances, Cr. Rev. Food Sci., 48, 137-159, 2008.

EFSA AHAW Panel - EFSA Panel on Animal Health and Animal Welfare: Scientific Opinion on welfare aspects of the use of perches for laying hens, EFSA J., 13, 4131, doi:10.2903/j.efsa.2015.4131, 2015.

Ekstrand, C., Algers, B., and Svedberg, J.: Rearing conditions and foot-pad dermatitis in Swedish broiler chickens, Prev. Vet. Med., 31, 167-174, 1997.

Estevez, I., Tablante, N., Pettit-Riley, R. L., and Carr, L.: Use of cool perches by broiler chickens, Poultry Sci., 81, 62-69, 2002.

Fanatico, A. C., Cavitt, L. C., Pillai, P. B., Emmert, J. L., and Owens, C. M.: Evaluatin of slow-growing broiler genotypes grown with and without outdoor access: Meat quality, Poultry Sci., 84, 1785-1790, 2005.

Faure, J. M. and Jones, R. B.: Effect of sex, strain and type of perch on perching behavior in the domestic-fowl, Appl. Anim. Behav. Sci., 8, 281-293, 1982.

Gouveia, K. G., Vaz-Pires, P., and da Costa, P. M.: Welfare assessment of broilers through examination of haematomas, footpad dermatitis, scratches and breast blisters at processing, Anim. Welfare, 18, 43-48, 2009.

Hashimoto, S., Yamazaki, K., Obi T., and Takase, K.: Footpad Dermatitis in Broiler Chickens in Japan, J. Vet. Med. Sci., 3, 293 297, 2011.

Haye, U. and Simons, P. C. M.: Twisted legs in broilers, Brit. Poultry Sci., 19, 549-557, 1978.
Hongchao, J., Jiang, Y., Song, Z., Zhao, J., Wang, X., and Lin, H.: Effect of perch type and stocking density on the behavior and growth of broilers, Anim. Prod. Sci., 54, 930-941, 2013.

Hughes, B. O. and Elson, H. A.: The use of perches by broilers in floor pens, Bri. Poultry Sci., 18, 715-722, 1977.

Jong, I. C. de, Gunnink, H., and van Harn, J.: Wet litter not only induces footpad dermatitis but also reduces overall welfare, technical performance, and carcass yield in broiler chickens, J. Appl. Poultry. Res., 23, 51-58, 2014.

LeVan N. F., Estevez, I., and Stricklin, W. R.: Use of horizontal and angled perches by broiler chickens, Appl. Anim. Behav. Sci., 65, 349-365, 2000.

Martland, M. F.: Ulcerative dermatitis in broiler chickens: the effects of wet litter, Avian Pathol., 14, 353-364, 1985.

Mayne, R. K.: A review of the aetiology and possible causative factors of foot pad dermatitis in growing turkeys and broilers, Worlds Poultry. Sci. J., 61, 256-267, 2005.

Michel, V., Prampart, E., Mirabito, L., Allain, V., Arnould, C., Huonnic, D., LeBouquin, S., and Albaric, O.: Histologicallyvalidated footpad dermatitis scoring system for use in chicken processing plants, Brit. Poultry Sci., 53, 275-281, 2012.

Newberry, R. C. and Hall, J. W.: Use of pen space by broiler chickens: Effects of age and pen size, Appl. Anim. Behav. Sci., 25, 125-136, 1990.

Nielsen, B. L.: Breast blisters in groups of slow-growing broilers in relation to strain and the availability and use of perches, Brit. Poultry Sci., 45, 306-315, 2004.

Pettit-Riley, R. and Estevez, I.: Effects of density on perching behavior of broiler chickens, Appl. Anim. Behav. Sci., 71, 127-140, 2001.

SAS Institute: SAS User's Guide Statics Edition, SAS Institute Inc. NC, USA, 2001.

SCAHAW - Scientific Committee on Animal Health and Animal Welfare: The Welfare of Chickens Kept for Meat Production (Broilers), European Commission, Health and Consumer Protection Directorate-General, Brussels, Belgium, March 2000.

Shepherd, E. M. and Fairchild, B. D.: Footpad dermatitis in poultry, Poultry Sci., 89, 2043-2051, 2010.

TSE - Turkish Standard Institute: Animal feed-determination of metabolizable energy (chemical method), Publ. number 9610, Ankara, Turkey, 1-32, 1991.

Van der Aa, A: Clay minerals to fight footpad lesions, World Poult., 12, 15-17, 2008.

Ventura, B. A., Siewerdt, F., and Estevez, I.: Effects of barrier perches and density on broiler leg health, fear, and performance, Poultry Sci., 89, 1574-1583, 2010.

Ventura, B. A., Siewerdt, F., and Estevez, I.: Access to Barrier Perches Improves Behavior Repertoire in Broilers, PLoS ONE, 7, e29826, doi:10.1371/journal.pone.0029826, 2012.

Zhao, J. P., Jiao, H. C., Jiang, Y. B., Song, Z. G., Wang, X. J., and Lin, H.: Cool perches improve the growth performance and welfare status of broiler chickens reared at different stocking densities and high temperatures, Poultry Sci., 92, 1962-1971, 2013. 